\title{
Visual tools for business model innovation: Recommendations from a cognitive perspective
}

DOI:

10.1111/caim.12208

\section{Document Version}

Accepted author manuscript

Link to publication record in Manchester Research Explorer

\section{Citation for published version (APA):}

Taeuscher, K., \& Abdelkafi, N. (2017). Visual tools for business model innovation: Recommendations from a cognitive perspective. Creativity and Innovation Management, 26(2), 160-174. https://doi.org/10.1111/caim.12208

\section{Published in:}

Creativity and Innovation Management

\section{Citing this paper}

Please note that where the full-text provided on Manchester Research Explorer is the Author Accepted Manuscript or Proof version this may differ from the final Published version. If citing, it is advised that you check and use the publisher's definitive version.

\section{General rights}

Copyright and moral rights for the publications made accessible in the Research Explorer are retained by the authors and/or other copyright owners and it is a condition of accessing publications that users recognise and abide by the legal requirements associated with these rights.

\section{Takedown policy}

If you believe that this document breaches copyright please refer to the University of Manchester's Takedown Procedures [http://man.ac.uk/04Y6Bo] or contact uml.scholarlycommunications@manchester.ac.uk providing relevant details, so we can investigate your claim.

\section{OPEN ACCESS}




\title{
Visual Tools for Business Model Innovation: Recommendations from a Cognitive Perspective
}

\author{
Karl Täuscher* \\ Bayreuth University \\ Chair of Strategic Management \& Organization \\ Prieserstraße 2, 95444, Bayreuth, Germany \\ Leipzig University \\ Chair of Innovation Management \\ Augustusplatz 10, 04109 Leipzig, Germany \\ Nizar Abdelkafi \\ Fraunhofer IMW \\ Group Business Models: Engineering \& Innovation \\ Neumarkt 9-19, 04109, Leipzig, Germany \\ Leipzig University \\ Chair of Innovation Management, \\ Augustusplatz 10, 04109 Leipzig, Germany
}

Täuscher, Karl \& Abdelkafi, Nizar (2017): Visual Tools for Business Model Innovation: Recommendations from a Cognitive Perspective. Creativity and Innovation Management 26(2) 2017: 160-174. Doi: 10.1111/caim.12208.

Available online at: http://onlinelibrary.wiley.com/doi/10.1111/caim.12208/full

*Corresponding author. 


\title{
Visual Tools for Business Model Innovation: Recommendations from a Cognitive Perspective
}

\begin{abstract}
Managers involved in business model innovation (BMI) encounter a series of cognitive challenges. Although cognition research provides important insights into how visual tools can reduce cognitive challenges, it does not address the effective design of business model tools. To advance our understanding in this area, this research applies a cognition-centered perspective to analyze different visual business model representations. It builds upon a systematic literature review that identifies a selection of 45 visual representations from the academic literature and a sample of 50 visualizations from outside the academic realm. A content analysis of the sample reveals that all visual business model representations can be classified into three complementary categories, leading to a novel framework for distinguishing business model understandings. After assigning each visual representation to the framework, we use findings from the cognition literature to derive recommendations on how to select suitable graphic forms for different phases of the BMI process. Thus, this research contributes to the broader understanding of how visual tools can support business model innovation at a cognitive level.
\end{abstract}

Key Words: Business model, Business model innovation, Visualization, Innovation Tools 


\section{Introduction}

Managers are increasingly confronted with the task of creating innovative business models. Literature recognizes many challenges in the process of designing and innovating business models. Most commonly, managers lack an understanding of the business model concept itself and are easily overwhelmed by the task of generating and implementing new business model ideas (Chesbrough, 2010). Given the inherently complex and dynamic nature of business models (Casadesus-Masanell and Ricart, 2010; These phenomena and questions fundamentally motivate current business model research as evidenced by a recent calls for future business model research by (Demil et al. 2015):, 2015; Zott and Amit, 2013), business model innovation (BMI) requires not only creativity, but also a "structure and guidance to frame and focus thought" (Eppler et al., 2011). Yet, compared to other innovation processes, managers lack appropriate tools to help them cope with these cognitive challenges when developing new business models (Frankenberger et al., 2013). This observation seems to be surprising because of the plethora of visual representations proposed in the business model literature, thus suggesting a potential disconnect between these design artefacts and the cognitive challenges experienced by managers during BMI processes.

Visualization has been identified a key approach in designing and analyzing business models. Practical experience has shown that "[v]isual thinking is indispensable to working with business models" (Osterwalder and Pigneur, 2010). Visualization can support firms in better understanding and communicating their current business models, generating and developing new business model ideas and overcoming organizational innovation barriers (Eppler and Hoffmann, 2011). Visual business model representations are artefacts that stimulate collaborative innovation (Eppler and Hoffmann, 2012), reduce complexity (Doz and Kosonen, 2010), uncover hidden structures within a business model (CasadesusMasanell and Ricart, 2007), enable firms to communicate the business model effectively (Osterwalder, 2004), and represent a tool for knowledge sharing (Doganova and Eyquem-Renault, 2009). Although there are a variety of approaches for the visual representation of business models, they rarely build on design principles developed in visualization research. Scholars that have studied the design and use of visual 
artefacts provide clear evidence that the choice for a specific visualization type has an important impact on the user's cognitive processes and mental models (Card et al., 1999; Eppler and Bresciani, 2013; Eppler and Platts, 2009; Hegarty, 2011; Hyerle, 2009; Tversky, 2011; Upton, 1961). To draw an analogy, we can imagine a business model as an abstracted painting of a business. Paintings can either represent a specific view on an objective reality or represent the artist's impression. In the painting, the artist can highlight specific aspects of the real or imagined scenery through the selection and relative size of particular elements, the level of detail, or the colors of the picture. These artistic choices, influenced by the painter's purpose, artistic school, and the available tools and skills, will have a large impact on the perception of the represented scenery. Analogously, managers will develop and communicate different mental images of their businesses, depending on how they visually represent their business model (Eppler and Hoffmann, 2012).

The cognitive processes and mental models of a firm's decision maker shape the design of a firm's business model (Amit and Zott, 2015; Martins et al., 2015). While different streams disagree upon whether the business model concept refers to something real (Amit and Zott, 2001; Casadesus-Masanell and Ricart, 2010), or purely represents decision makers' cognitive models (Baden-Fuller and Mangematin, 2013; Baden-Fuller and Morgan, 2010), researchers from both streams recognize the importance of managerial cognition in business model design and innovation (Aversa et al., 2015; Berends et al., 2016; Bucherer et al., 2012; Martins et al., 2015).

Studying the link between visualization and cognition in BMI is challenging due to the specific nature of business model research. First, this research is spread over different research fields. Previous reviews of BM representations have been mostly limited to work in the area of information systems (IS), focusing on formal modelling approaches such as ontology design (Gordijn et al., 2005; Kundisch et al., 2012; Schuster and Motal, 2009). To overcome this limitation, our research takes a broad perspective on business model research that includes visual business model representations (VBMR) from different research domains, and those that are not based on formal notation. Second, the business model concept simultaneously developed outside the academic realm. In fact, the usage of the concept in practice has inspired early business model 
research (Mahadevan, 2000; Timmers, 1998). While many business model scholars have developed artefacts to serve a practice-oriented purpose (Bucherer et al., 2012; Spieth et al., 2014), the actual understanding and use of the business model concept by practitioners is rarely taken into account (George and Bock, 2011). Because of this, we explore the use of visual BM representations outside the academic realm. A Google image search for "business model" reveals that practitioners use a variety of visual forms to represent business models. However, they rarely build on the artefacts developed in the academic literature. This phenomenon relates to the academic-practitioner divide discussed for decades in the area of management science (Lilien, 2011). "The big problem with management science models is that managers practically never use them. There have been a few applications, of course, but the practice is a pallid picture of the promise" (Little, 1970, p. 466). To increase the relevance of academic research on business models, it can be a rewarding exercise to include also visualizations from outside the academic realm in the study.

Our research aims to support managers in choosing appropriate visualizations for BMI and simultaneously advance the theoretical understanding of business models. Toward this aim, it first reviews the cognitive challenges faced during BMI. Subsequently, it identifies existing visualizations from academia and practice through a systematic search strategy. Next, it develops a literature-based framework that allows a structured analysis and classification of these visual representations. Rather than focusing on how existing approaches should converge, we attempt to identify broad categories of representations with similar characteristics that support specific cognitive processes. Hence, this approach aims at developing a more nuanced understanding about how visual representations can support BMI, thus contributing to the literature on effective design and usage of artefacts during innovation processes. Consequently, we address two major research questions: How can we categorize existing visual representations of business models? Which cognitive functions are supported by specific types of visual business model representations? By taking a visualization perspective, we advance the theoretical understanding of business models as we develop a framework that identifies three main business model views. 


\section{Related research}

Before reviewing the visual business model representations (VBMR), this section begins with highlighting the potential value of visualization as artefacts for diverse managerial tasks. Subsequently, the dominant business model perspectives as well as the phases and tasks within the BMI process are reviewed.

\section{Visualization in management}

Visualization represents a type of language that communicates on a two or more dimensional space, while making use of diverse elements such as signs, arts, drawings, graphical designs, illustrations, or colors (Zhang, 2012). Visualization research identifies the mechanisms that allow humans and computers to perceive, use, and communicate visual information (McCormick et al., 1987). This field of research is located at the overlapping area between management studies, computer science, design, and psychology. It builds on insights from cognitive science into how visualizations influence cognitive processes (Larkin and Simon, 1987; Tversky, 2011), and how these insights can lead to design principles for visualization (Hegarty, 2011).

Visualization supports the cognitive processes of managers and augments the capacity of the human mind (Tversky, 2011). First, it constitutes an external storage for information, thus freeing up the working memory for other thinking processes (Hegarty, 2011). Second, it structures the information and spatially groups related bits of information together to enhance the representation of relationships (Larkin and Simon, 1987). Third, visualization is a means for overcoming an individual's cognitive overload through offloading the cognitive processes either on the individual's visual perception or haptic action. In other words, the cognitive load is reduced because the perceiver can additionally use his eyesight to process the information ("using vision to think"), or involves his haptic senses in the physical process of visualizing and experimenting with visualizations (Card et al., 1999). Forth, visualization provides multiple retrieval paths for accessing knowledge (O’Donnell et al., 2002). 
Apart from the support of cognitive processes, visualizations are conducive to organizational communication and collaboration effectiveness (Eppler and Bresciani, 2013). On the collective level, visualizations improve communication among working teams, between management and employees, and between the organization and its external stakeholders (Zhang, 2012). The pure process of visualization can enhance the collaboration effectiveness of management teams by creating a common understanding of mental models, a physical space for experimentation, and a tangible outcome of the collaboration process (Eppler and Bresciani, 2013). Visualizations further influence emotional processes by engaging employees and team members (Bresciani et al., 2011). While visualization has multiple benefits on collaboration, this research rather focuses on individual cognition.

The use of visualization techniques has a long tradition in management domains such as strategy, finance, or marketing (Zhang, 2012). Managers use sketches, visual metaphors, or conceptual diagrams to support idea generation, decision making, planning, knowledge sharing and learning. Management scholars increasingly deal with questions regarding the different purposes of visualization in management (Eppler and Bresciani, 2013), innovative forms to visualize information (Zhang, 2012), or the role of visualization tools in collaboration between managers (Bresciani et al., 2011). With a few exceptions (Phaal et al., 2009), business literature rarely explores the effectiveness of the visual representations used by the corresponding community of researchers and practitioners.

\section{Business models and business model innovation}

Research on business models is a rapidly growing field that is still in search for a strong theoretical foundation. The business model concept can be broadly defined as an organization's abstracted logic of value creation, delivery, and capture (Teece, 2010). Business model literature finds its roots in many wellestablished research branches such as strategic management (Amit and Zott, 2001), technology and innovation management (e.g., Chesbrough, 2007), or information systems (e.g., Gordijn and Akkermans, 2001). The lack of common theoretical foundations has led to many different understandings of business models (Zott et al., 2011). The literature has proposed different conceptualizations, reflecting an a priori 
disagreement of what a business model should actually represent (DaSilva and Trkman, 2013). As a consequence, scholars have concluded that research on business models does not converge towards a common theoretical framework or underlying theory (Zott et al., 2011), and therefore represents "a slippery construct to study" (Casadesus-Masanell and Zhu, 2013).

Business models have become subject to innovation themselves over the last years. Business model innovation has both been identified as a necessity and a key driver of firm success (Schneider and Spieth, 2013). Among others, innovative business models enable firms to enhance strategic flexibility (Bock et al., 2012), to respond appropriately to high environmental volatility (Pohle and Chapman, 2006; Zott and Amit, 2010), to improve the firm's sustainability performance (Pedersen et al., 2016) and organizational resilience (Carayannis et al., 2015; Carayannis et al., 2014), to achieve a competitive advantage (Chesbrough, 2010; Hamel, 2000; McGrath, 2010), and to drive financial performance (Aspara et al., 2010; Chesbrough and Rosenbloom, 2002). Some researchers argue that firms developing a highly innovative business model can create entirely new market areas (Chesbrough, 2010) or redefine the rules of competition (Kim and Mauborgne, 2014). Consequently, firms can capture (at least temporarily) a Schumpeterian innovation rent in terms of higher willingness-to-pay and customer loyalty (Zott and Amit, 2008, 2007). Besides, firms that frequently innovate their business models are expected to create reinforcing effects on product, service and process innovation (Zott and Amit, 2008). As such, many scholars emphasize the need for organizations to innovate their business model more frequently (Doz and Kosonen, 2010; Mitchell and Coles, 2003).

To better understand the role of visual artefacts in the process of BMI, we need to explore the competing understandings about how firms develop and change their business models. The majority of BM research is rooted in an understanding of business models as something real, existing outside managers' cognition (Martins et al., 2015). These scholars either consider business models as purposefully-designed systems (e.g., Amit and Zott, 2001; Casadesus-Masanell and Ricart, 2010; Zott and Amit, 2008, 2007) or as systems that emerge and change in an evolutionary manner (e.g., Demil and Lecocq, 2010; Sosna et al., 2010). While scholars that understand business models as purposefully-designed systems focus on identifying principles, patterns, elements, or configurations of successful business models (e.g., Abdelkafi and Täuscher, 2016; 
Casadesus-Masanell and Ricart, 2011; Osterwalder and Pigneur, 2010; Pateli and Giaglis, 2004; Shafer et al., 2005), scholars following the evolutionary view rather focus on the antecedents and organizational factors that foster or inhibit successful business models change over time (Berends et al., 2016; Chesbrough, 2010; McGrath, 2010; Suárez et al., 2013). In the last years, however, some scholars have additionally conceptualized business models as cognitive artefacts (Baden-Fuller and Haefliger, 2013; Baden-Fuller and Mangematin, 2013; Baden-Fuller and Morgan, 2010; Massa and Tucci, 2014). These scholars consider business models as cognitively constructed representations that exist in the heads of the organization's decision makers (Baden-Fuller and Haefliger, 2013). Business Models are therefore conceptualized as reflections of cognitive structures (Doz and Kosonen, 2010), managerial schemas (Martins et al., 2015), or a cognitive instrument (Baden-Fuller and Mangematin, 2013). As a consequence, related research aims at "explicating the cognitive logic and processes through which schemas can be changed to ideate and design new business models in the absence of exogenous change" (Martins et al., 2015, p. 100). Acknowledging the existence of both streams, we believe that visual artefacts constitute an essential element to support the BMI process, independently of whether the BM designates a real system that operates in an objective world or a manager's mental representation that reflects a subjective model that is strongly related to the individual.

\section{Cognitive barriers in the BMI process}

Business model scholars started to identify cognitive barriers that inhibit BMI (Chesbrough, 2010; Chesbrough and Rosenbloom, 2002; Eppler and Hoffmann, 2011; Martins et al., 2015). Table 1 provides an overview of the barriers in three distinctive phases of the BMI process. The BMI 4I-framework by Frankenberger et al. (2013) consists of four phases: initiation, ideation, integration, and implementation. Because the barriers in the fourth phase (implementation) are mainly due to the inability of the organization to effectively coordinate innovation processes (Doganova and Eyquem-Renault, 2009), we only focus on the barriers that arise during the first three phases. 
Table 1: Overview of cognitive barriers and related skills in BMI process

\begin{tabular}{|c|c|c|c|}
\hline BMI phase & Initiation & Ideation & Integration \\
\hline Key purpose & $\begin{array}{l}\text { Gaining an understanding about the } \\
\text { key value logic of the current BM, } \\
\text { its potential limitations and } \\
\text { absorbing knowledge from the firm's } \\
\text { environment }\end{array}$ & $\begin{array}{l}\text { Generating and } \\
\text { selecting creative } \\
\text { ideas on how to } \\
\text { innovate the } \\
\text { current BM }\end{array}$ & $\begin{array}{l}\text { Developing a complete and } \\
\text { consistent BM that specifies } \\
\text { all relevant aspects in a } \\
\text { holistic way }\end{array}$ \\
\hline $\begin{array}{l}\text { Key innovation } \\
\text { barrier(s) }\end{array}$ & $\begin{array}{l}\text { Complexity of the business model } \\
\text { concept }\end{array}$ & $\begin{array}{l}\text { Overcoming } \\
\text { dominant business } \\
\text { logic }\end{array}$ & $\begin{array}{l}\text { Integrating and aligning all } \\
\text { pieces of the BM and sharing } \\
\text { the knowledge across intra- } \\
\text { and inter-organizational } \\
\text { boundaries }\end{array}$ \\
\hline $\begin{array}{l}\text { Selected cognitive } \\
\text { abilities to overcome } \\
\text { innovation barriers }\end{array}$ & $\begin{array}{l}\text { Absorbing complexity, and } \\
\text { (re)framing the design problem }\end{array}$ & $\begin{array}{l}\text { Taking distance } \\
\text { from and } \\
\text { abstracting the } \\
\text { dominant logic }\end{array}$ & $\begin{array}{l}\text { Focusing attention on missing } \\
\text { information and } \\
\text { communicating one's thinking } \\
\text { effectively to others }\end{array}$ \\
\hline
\end{tabular}

The initiation phase aims at analyzing the current business model and framing the innovation problem. The execution of this phase can be disrupted when managers are unable to frame the innovation problem in an effective way. Such type of barriers are generally acknowledged in the design thinking literature (Dorst, 2011). Because of their systemic and complex nature (Pateli and Giaglis, 2004; Zott et al., 2011), successful BMI initiation requires the cognitive absorption of this complexity (Eppler and Hoffmann, 2011).

The ideation phase aims at generating creative ideas for BMI. The successful generation of innovative ideas is inhibited, if the company cannot overcome the dominant logic of the existing business model (Chesbrough, 2010; Chesbrough and Rosenbloom, 2002). The dominant logic, a concept from strategic management (Bettis and Prahalad, 2009; Prahalad and Bettis, 1986), denotes the set of mental maps created in the minds of top managers due to successful events that happened in the past. These events can be related, for instance, to how the firm has so far created and captured value; in other words the business model. Once established, these mental maps shape the cognitive orientation and decisions in subsequent managerial challenges. Hence, the main cognitive challenge in ideation relates to thinking outside the dominant logic, commonly referred to as 'out of the box' (Frankenberger et al., 2013). Managers can achieve this by abstracting or cognitively distancing themselves from the dominant logic (Doz and Kosonen, 2010). 
However, the quality of the ideation phase simultaneously depends on the appropriateness of the generated business model ideas. Thus, guiding 'out of the box' thinking within an appropriate solution space presents an additional cognitive challenge.

The integration phase equally requires tools that structure and guide thought (Eppler et al., 2011; Martins et al., 2015). In this phase, managers transform the generated ideas into complete and consistent business models. The key barriers consist of the managers' inability to align all business model elements and share this knowledge with others (Frankenberger et al., 2013). Hence, managers need to focus their thoughts on recognizing the missing information about parts of the business model as well as potential inconsistencies. Furthermore, they need to be able to mentally represent this knowledge in a way that can be effectively shared with others (Eppler and Hoffmann, 2011). In summary, effective BMI requires the support of tools that help absorbing complexity, (re)framing the design problem, fostering 'out of the box' thinking, guiding thought and focusing attention, while allowing knowledge sharing with others. 


\section{Research Methodology}

\section{Selection of visual business model representations}

Previous research has focused exclusively on comparing entire notations of formal BM representation systems (Kundisch et al., 2012). This work focuses on visual representations of the business model as unit of analysis. We define visual business model representations (VBMR) as self-contained, purposefully designed, two-dimensional images that contain graphic and textual elements to convey information about a business model understanding or a specific business model. In other words, we do not consider visual representations of the $\mathrm{BMI}$ process, $\mathrm{BM}$ classifications, other creativity tools, or visualizations of a technique other than the BM itself.

We apply a twofold search strategy to identify a broad and diverse set of visual representations of business models. To identify BM representations within the academic literature, we apply a search strategy using the EBSCO Business Source Complete database as a starting point (as applied by Zott et al., 2011). We search for publications in English that contain the term "business model" in the title and that are published after the year 1999. The EBSCO database allows one to limit the search to those sources that contain at least one image (e.g. graph, map, diagram). The search strategy leads to 275 sources that are complemented with articles identified within these sources and within previous literature reviews on business models (Morris et al., 2005; Zott et al., 2011; Schneider and Spieth, 2013; Spieth et al., 2014). In the case of the four books included in the sample, we screen the content to identify the main type of VBMR. For instance, Osterwalder and Pigneur's book on business model design contains a number of VBMRs but emphasizes the Business Model Canvas as the main artefact. In this case, the business model canvas is included to the sample, while other visualizations found in the book are not. We then screen these preselected sources to limit the sample to those visualizations that broadly relate to business models, leading to a sample of 152 visualizations from academic publications. In only a few cases, a single source contains more than one BM representation. 
The selected 152 images from the academic search then undergo a preliminary analysis. For this purpose, each image is printed on an individual sheet of paper. First, we screen all images to get a preliminary overview of the overall range of visualizations. Next, we exclude the images that represent process models or visualize tools for business model innovation (e.g. single business model patterns). We also eliminate representations of business model-related knowledge such as the graphic representation of business model design themes by Amit and Zott (2001), graphic structuring of business model typologies (Timmers, 1998), or the visual distinction of the business model concept from related concepts such as strategy and operations (Osterwalder, 2004). In these cases, we use the figure's description to decide, whether the image represents a BM or visualizes BM-related knowledge. Finally, we select one representative visualization from each source to reduce redundancies. For instance, Casadesus-Masanell and Ricart (2007) provide nine images with similar notations to represent different BMs at varying degrees of granularity. Due to the similarity of the applied notations, we select only one VBMR from the nine graphics. We also exclude images from more recent sources that are almost identical to those found in earlier research. The final sample, as depicted by figure 1, contains VBMRs from 45 different sources. We also exclude images from more recent sources that are almost identical to those found in earlier research. The final sample, as depicted by figure 1, contains VBMRs from 45 different sources. 
Figure 1: Visual business model representations in academic sources.

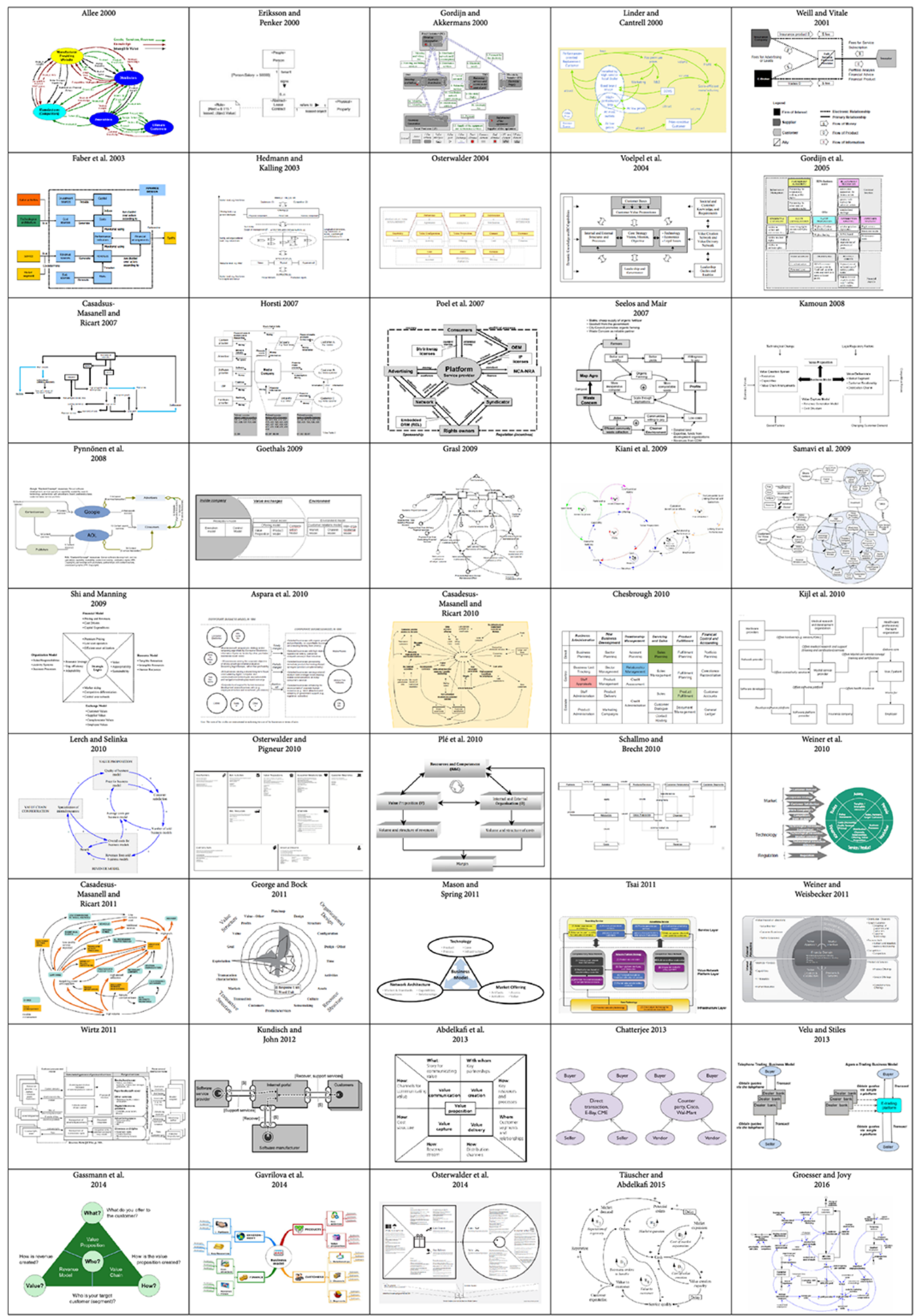


Figure 2: Visual business model representations outside academic sources

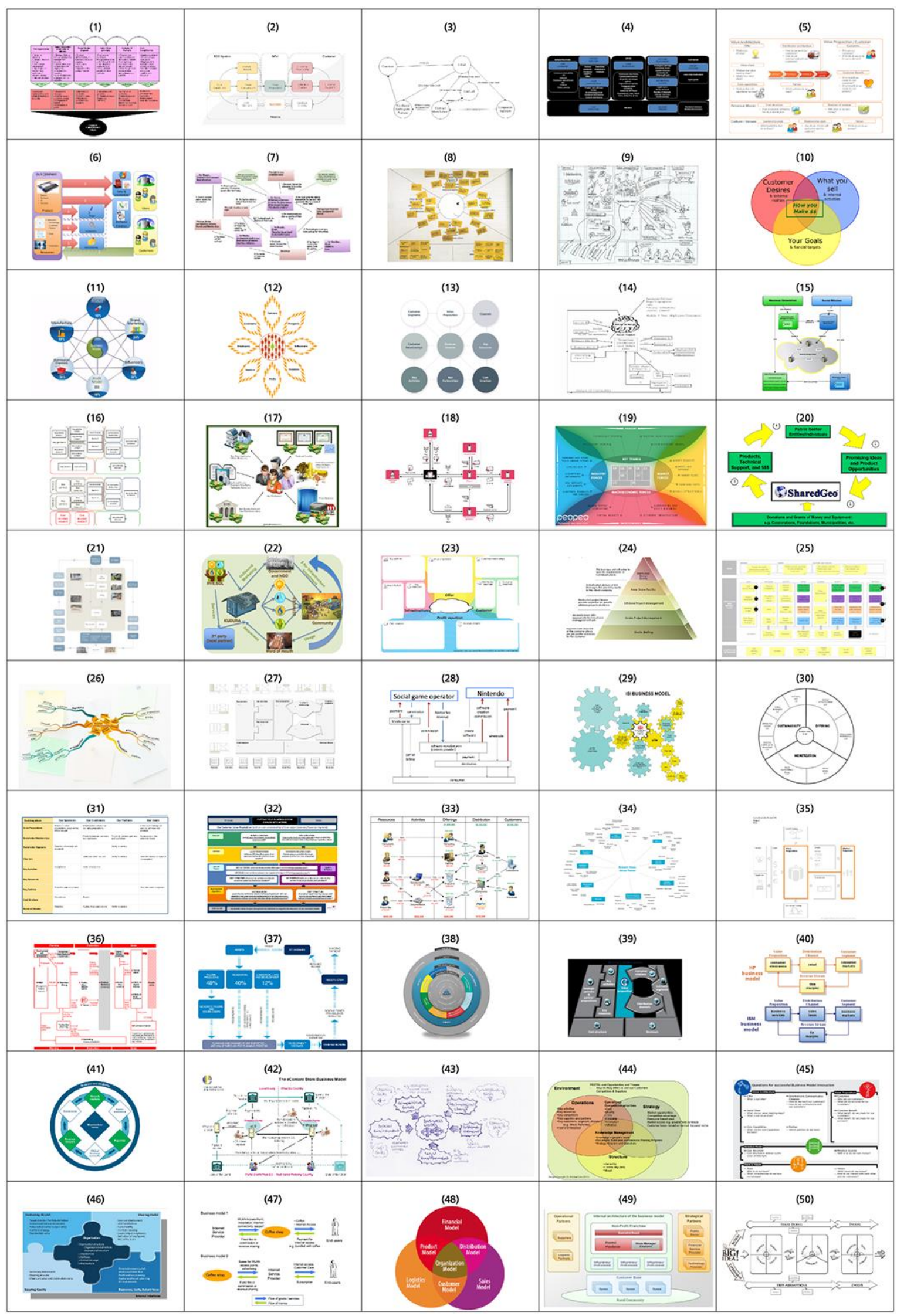


To identify a comparable sample of visualizations outside the academic realm, we apply a Google image search for the term "Business Model". While we acknowledge a potential bias from incorporating only publicly available images, we consider the search strategy as most viable for the purpose of this research. We restrict our search to the first 1000 images shown in the search results. Based on these 1000 images, we conduct a preliminary selection, eliminating those images that are not representing visual representations of business model (e.g. image of book cover). The selection process results in 274 different images that are related to business models. Overall, the practitioner sample contains more than 30 versions of the Business Model Canvas by Osterwalder and Pigneur (2010), thus only differing in their color or shape of lines. To provide a similar number of VBMRs in the practitioner sample compared to the academic sample, we eliminate redundant images and visualizations with low information content. At the end of the selection process, we retain 50 visualizations (figure 2).

\section{Framework and analysis of VBMRs}

The visualizations are analyzed in regard to two complementary dimensions: content and graphic form. These two dimensions are in line with previous work in the field of strategy visualization (Eppler et al., 2009). The content dimension refers to the information that is visually conveyed through the use of symbols and other notational elements. Since a classification system for VBMRs does not exist yet, we propose a novel framework. The classification aims at distinguishing VBMRs based on their notational patterns instead of theoretical underpinnings or word choices. To do so, we arrange the printed visualizations on blackboards and collaboratively identify common patterns in their content. The process is repeated with additional BM researchers until we arrive at categories that can capture all VBMRs in the sample. We find that all identified VBMRs use representations that are based on elements, transactions between actors and/or causal relations. Finally, the co-authors independently assign each VBMR to one of the defined categories. If this exercise leads to different assignments for a VBMR, the co-authors discuss and analyze the corresponding VBMR in-depth, until they settle for one category. 
The second dimension refers to the graphic form of the visualization. While there are several frameworks that classify graphic forms, we select the influential framework proposed by Hyerle (2009), based on the seminal work by Upton (1961). This framework classifies graphical representations according to three categories: graphic organizers, brainstorming webs, and conceptual maps. This classification covers the full range of tools for thinking creatively, organizationally, and conceptually. Graphic organizers are generally characterized by their pre-defined form that allows arranging specific textual content. These graphic forms generally serve as tools for analytical structuring and communicating information. The category of brainstorming webs contains graphic forms that are open-ended with no explicit design and idiosyncratic, allowing a continuous development of the visualization. They often spread from a center and usually result from the synthesis of symbol-based drawings and textual elements. While brainstorming webs help 'out of the box' thinking, graphic organizers support structuring thinking into boxes. Conceptual maps can be considered as a combination of brainstorming webs and graphic organizers. They build on predefined and consistent notations - often including arrows and other symbols - but are open-ended. Thus, they allow integrating both creative and analytical thinking. The analysis of the graphic forms by means of the framework by Hyerle (2009) allows us to generate insights into the effectiveness of different graphic forms to support cognition. As we did with the contents, we assign each VBMR to one of the defined categories of the graphic forms. Whereas at the content level, a visual representation may combine different business model views, at the graphical level, a VBMR is allocated to a single category.

\section{$4 \quad$ Analysis and results}

This section first allocates the different visual representations to the identified classes that are derived from the analysis of contents. Subsequently, it assigns VBMRs to categories of graphic forms. In addition, we derive patterns within and between the two samples of visual representations by academics and practitioners. 


\section{Content of visual representations}

The framework for the classification of the business model contents consists of an elements view, a transactional view and a causal view. Visualizations based on the elements view of business models visually convey a number of predefined elements. Usually, these representations require the user to fill out appropriate textual information that represents the firm's key business model choices with respect to each element (e.g. retailing as a potential option for the element Distribution Channel). Characteristically, those visualizations apply some form of verb-noun combinations. To decide whether an image belongs to this category, we ask the question: does the graphic visually reveal the specification of set of predefined elements? A VBMR is assigned to the elements view when it contains a specific specification of different business model elements, or if it represents a template to be filled out with such information.

Visualizations that rely on a transactional view of business models are characterized by the use of boxed objects - mostly representing actors - connected to each other by means of arrows. The arrows generally represent flows of cash or tangible resources between the different actors. In this case, we ask the question: does the image reveal a system of transactions between different objects?

Visualizations based on the causal view of business models generally use arrows that connect different textual elements. Arrows generally represent a causal connection between the elements. Thus, we ask the question: does the visual representation reveal major causalities between the textual elements.

Since all three questions are answered independently, each visual representation can be assigned to more than one category. Figure 3 represents all three categories and the assigned visualizations. To improve readability of the figure, the names of the authors are provided if the visual representation is found in academic literature; numbers are used to refer to the graphical representations taken from practitioner sources.

Figure 3: Framework for categorizing visual business model representations based on content 


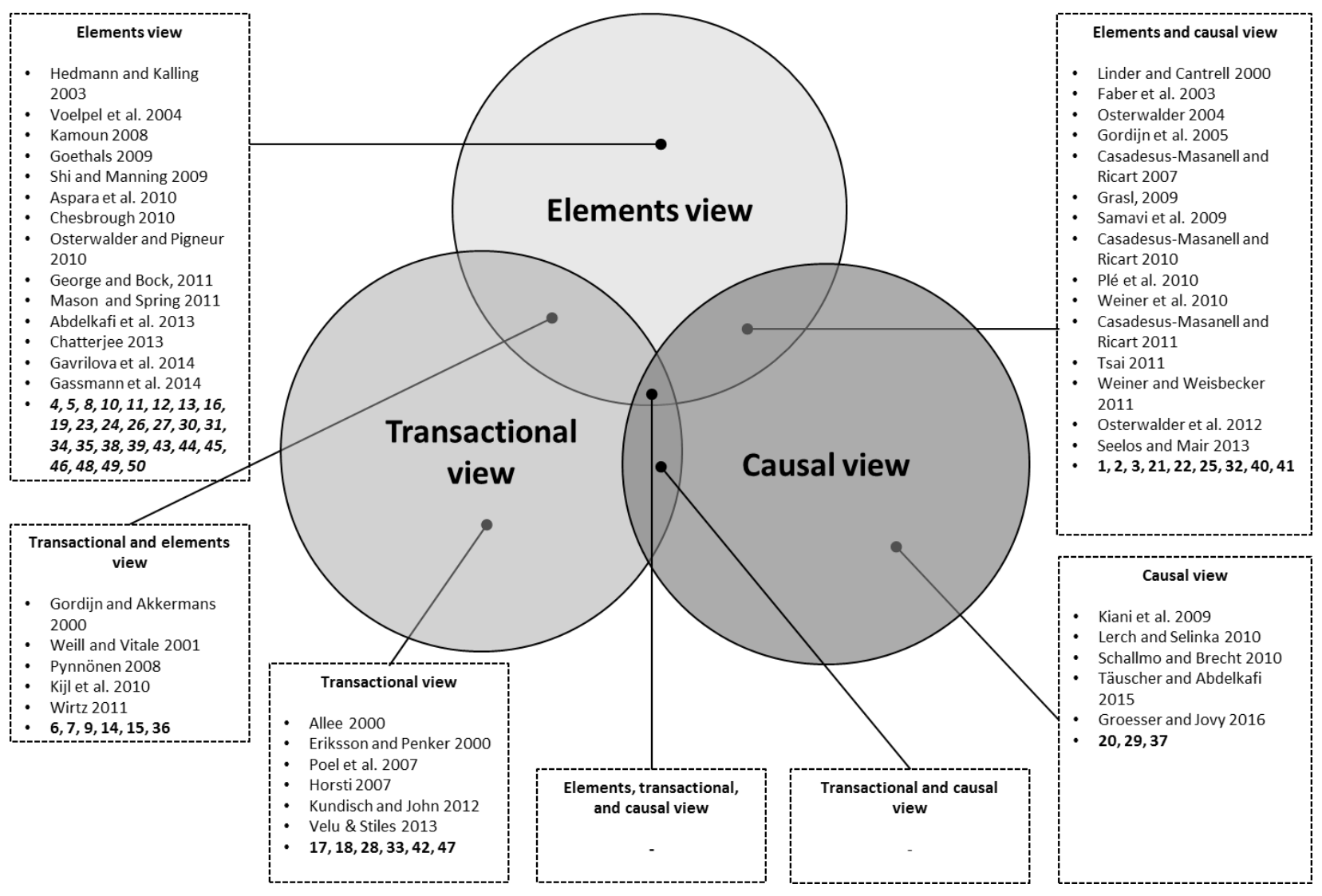

The analysis of the content leads to many insights. First, the majority of visualizations apply an elements view (exclusively or in combination with other views). The group of visualizations that only use the elements view consists - among others - of the well-accepted frameworks (e.g. Osterwalder and Pigneur, 2010) that use visual templates to structure business model information (Hedman and Kalling, 2003). Moreover, a large sample of visualizations combines the elements view and the causal view, leading, for instance, to a combination of causal-loop diagrams with the specification of particular choices (CasadesusMasanell and Ricart, 2011, 2010, 2007; Faber et al., 2003; Grasl, 2009; Linder and Cantrell, 2000; Osterwalder, 2004; Weiner and Weisbecker, 2011). Second, only a few visualizations focus the firm's transactions with its partner organizations. For instance, Poel et al. (2007) represent a system of actors and flows. Other visual approaches to business models combine a transactional structure with a detailed description of elements such as key activities or key resources (e.g., Weil and Vitale 2001). The combination of the transactional and elements view of business models appears both in pre-defined templates as well as flexible notations such as the e3 value map by Gordijn and Akkermans (2001), who describe the business 
model as a transaction network that includes activities for every actor. Another example is the notation proposed by Wirtz (2011) that consists of an outer structure to represent the transactions and an inner structure to display the key elements chosen by the firm. Surprisingly, no single approach combines the transactional and causal views. Third, the number of individual components (elements, transactions, causal links) varies considerably, ranging from four (e.g. image 10) to more than twenty elements (19; 45; Samavi et al., 2009). Recapitulating, business model understanding is largely dominated by an elements-driven view in a stand-alone way or in combination with other views.

The comparison of the two sub-samples supports the practitioner-researcher divide that has been frequently discussed in the literature. About half of the representations in the practitioner sample apply a one-sided approach that focuses on a pure elements view (figure 3). In other words, there is a tendency among practitioners to view the business model as the visual arrangement of a firm's specific elements, rather than a system of causes and consequences, or transactions. Furthermore, the practitioners' representations rarely draw on formal notations (e.g. causal loop diagrams) in contrast to academia (e.g. Casadesus-Masanell and Ricart, 2011, 2010; Kiani et al., 2009; Lerch and Selinka, 2010; Täuscher and Abdelkafi, 2015). Some practitioner visualizations borrow elements from formal notations such as arrows, but do not use them consistently as prescribed in formal modelling notations such as causal-loop diagrams(Images 20, 29, 37). Another distinction between the practitioners' and scientists' representations relates to the boundaries of the business model concept. Although the business model concept is often viewed as an intermediate layer between the upper layer of strategy and the lower layer of operations (Zott et al., 2011), practitioners often include in their visualizations elements from the firm's operational layer such as specific business processes or detailed financial flows. In other cases, VBMRs include elements from strategy such as the firm's mission and vision statement, or elements from the macro environment such as the technological environment, thus embedding the business model into a broader context. 


\section{Analysis of graphic forms}

Graphic forms can be categorized as graphic organizers, brainstorming webs, or conceptual maps (Hyerle, 2009). The analysis reveals a strong dominance of graphic organizers in the sample. Graphic organizers provide a visual structure to textual information. In this category, we find tabular representations, which are highly common among academics (Abdelkafi et al., 2013; Goethals, 2009; Hedman and Kalling, 2003; Kamoun, 2008; Osterwalder and Pigneur, 2010; Shi and Manning, 2009) and practitioners (1; 9; 16; 23; 25; $27 ; 32 ; 35 ; 39 ; 45)$. These representations consist of a number of boxed elements arranged in a static order without including other elements such as as arrows or flows. Our sample shows that practitioners have proposed several modifications of the Business Model Canvas by Osterwalder and Pigneur (2010). Many practitioner visualizations also resemble conceptual maps and use an arrow-based notation, whereby the arrows only reflect some connectedness and do not denote the same kind of relationships between the boxes $(7 ; 11 ; 13 ; 17 ; 20 ; 22 ; 40 ; 41)$. As such, the arrows are not used consistently. A similar type of visualizations centers around entities in boxes that represent specific activities described by verb-noun combinations. These visualizations, which resemble workflow diagrams, have been identified only in the practitioner sample $(21,37)$. Besides, we identify a number of visualizations that apply specific forms of graphic organizers such as pyramids (24), Venn diagrams (10;44; 48), circular forms (Weiner et al., 2010; 30; 38), a template that combines circular and tabular representation (Weiner and Weisbecker, 2011), a template with a triangular form (Gassmann et al., 2014), a radar diagram to visually compare the strength of different business model elements (George and Bock, 2011), a flower that represents business model elements as pedals (12), or a puzzle (46). In the academic literature, many visual representations aim at representing the authors' understanding of the business model concept in general (Abdelkafi et al., 2013; Gassmann et al., 2014; George and Bock, 2011; Goethals, 2009; Hedman and Kalling, 2003; Mason and Spring, 2011; Plé et al., 2010; Shi and Manning, 2009; Weiner and Weisbecker, 2011). Only a few exceptions explicitly develop an artefact for the support of practitioners in business model design and innovation (e.g. Osterwalder, 2014, 2004; Osterwalder and Pigneur, 2010). 
The category of brainstorming webs consists of only five visualizations. Four of them have mind mapsimilar forms (Gavrilova et al., 2014; 26; 34; 43). An additional visualization (29) uses metaphor-a system of gears-to visualize the business model elements and how they complement each other. Note that the academic sample contains a single visualization that belongs to the brainstorming web category. The authors (Gavrilova et al., 2014) transformed the business model elements in Osterwalder and Pigneur's canvas to a mind map and claim that this new representation can assist managers during the process of business model innovation through cognitive support in communicating, sharing and manipulating business model knowledge.

The category of conceptual mapping is highly heterogeneous with many visualization types. A first type designates a sequence of actors (represented in boxes) related to each other by means of arrows. This graphic form is equally applied by academics (Chatterjee, 2013; Gordijn and Akkermans, 2001; Grasl, 2009; Horsti, 2007; Kundisch and John, 2011; Poel et al, 2007; Velu and Stiles, 2013; Weill and Vitale, 2001; Wirtz, $2011)$ and practitioners $(3 ; 6 ; 7 ; 15 ; 18 ; 28 ; 31 ; 36 ; 47)$. The representation by Linder and Cantrell (2000) can be described as a so-called concept map. Concept maps are "graphical tools for organizing and representing knowledge. Concepts, usually enclosed in circles or boxes of some type, and relationships between concepts indicated by a connecting line linking two concepts. Words on the line, referred to as linking words or linking phrases, specify the relationship between the two concepts" (Novak and Cañas, 2008). Several visualizations (Kiani et al., 2009; Lerch and Selinka, 2010) utilize the notation of causalloop diagramming from System Dynamics. Causal-loop diagrams (CLDs) allow one to flexibly represent the causal connections of system of elements. Such representations make it possible to recognize certain structural elements such as feedback loops within a system. Casadesus-Masanell and Ricart (2007, 2010), and Seelos and Mair (2007) have developed unique notations that combine the core notation of CLDs with other symbols (e.g. color-coding). A representation by Grasl (2009) uses the notation of stock and flow diagrams. In this notation, stocks represent entities such as money, resources, or inventories that are characterized by a path dependency. As such, they accumulate and/or deplete over time. Flows represent the streams that cause stocks to change. Interestingly, we find no usage of conceptual mapping in the sample 
of practitioner visualizations. The review of academic research shows that most of the papers that contain visualizations aim at describing (competing) business models (Casadesus-Masanell and Ricart, 2007; Velu and Stiles, 2013), analyzing the functionality and effectiveness of business models (Groesser and Jovy, 2016; Lerch and Selinka, 2010; Täuscher and Abdelkafi, 2015) or developing a formal notation for BM management (Wirtz, 2011). In the following, we discuss the implications of our findings for business model innovators and academics.

\section{Discussion and implications}

\section{Suitability of identified VBMR in BMI process}

Different artefacts can support different types of thinking processes and therefore address different cognitive cabailities. To analyze the suitability of the VBMR in tackling the identified BMI challenges, we draw on cognition research in the area of visualization. The results are summarized in table 2 .

Most practitioner and academic sources use graphic organizers, which are-according to the visualization literature (e.g. Hyerle, 2009)—specifically supportive to providing structures to information. Structures can guide thoughts and enable one to focus attention within a predefined space. The ability of structuring information is a cognitive skill that is most required during the integration phase of BMI. Because graphic organizers support the structuring of information, they can reduce complexity in learning processes. As such, they can be used at early stages of business model innovation to support the initiation phase. However, graphic organizers are less suited for sparking creative thinking (Hyerle, 2009). Therefore, they do not seem to be particularly supportive for the ideation phase. Surprisingly, these artefacts - most prominently the Business Model Canvas - are often applied by practitioners to generate innovative business model ideas (Eppler et al. 2011). This contradiction is further supported by research that experimentally compares the effectiveness of the Business Model Canvas in collaborative business model innovation (Eppler et al., 2011; Eppler and Hoffmann, 2012). In this research, a test group using the Business Model Canvas (BMC) was compared to a test group using tangible artefacts and a control group using a white piece of paper. The 
results do not support the hypothesis that the BMC increases the ideation performance in terms of perceived creativity or innovation output. In fact, the researchers found that “...the template (...) improves perceived collaboration, [but] decreases perceived creativity" (Eppler et al., 2011, p. 1334). Nevertheless, we propose that graphic organizers could also support the ideation phase, if the user is highly creative and trained to think 'out-of -the-box'. In addition, recent experimental research argues that the use of graphic organizers such as the BM Canvas in the classroom can 'increase students' awareness of and reflection on the importance of business models and/or their building blocks" (Hoveskog et al., 2015, p. 178). Regarding the type of contents, graphic organizers generally use an elements view (e.g. Abdelkafi et al., 2013) or a combination of elements and causal view (e.g. Plé et al., 2010). They also seem to be effective tools for describing, integrating, comparing, and classifying business models. 
Table 2: Comparison of conceptual maps, brainstorming webs and graphic organizers

\begin{tabular}{|c|c|c|c|}
\hline Graphic form & $\begin{array}{c}\text { Conceptual maps } \\
\text { (CM) }\end{array}$ & $\begin{array}{l}\text { Brainstorming } \\
\text { webs }(\mathrm{BW})\end{array}$ & $\begin{array}{c}\text { Graphic organizers } \\
\text { (GO) }\end{array}$ \\
\hline Definition & $\begin{array}{l}\text { CM describe } \\
\text { diagrams that depict } \\
\text { relationships } \\
\text { between concepts, } \\
\text { objects, or ideas to } \\
\text { organize and } \\
\text { structure knowledge. }\end{array}$ & $\begin{array}{l}\text { BW describe radial } \\
\text { diagrams that } \\
\text { represent concepts } \\
\text { hierarchically in an } \\
\text { open-ended } \\
\text { framework. }\end{array}$ & $\begin{array}{l}\text { GO represent diagrams } \\
\text { with pre-defined visual } \\
\text { arrangements. }\end{array}$ \\
\hline $\begin{array}{l}\text { Function of visual } \\
\text { representations }\end{array}$ & $\begin{array}{l}\text { CM support } \\
\text { analytical thinking } \\
\text { by absorbing } \\
\text { complexity for } \\
\text { recognizing the } \\
\text { systemic logic of a } \\
\text { particular problem } \\
\text { field }\end{array}$ & $\begin{array}{l}\text { BW foster creativity } \\
\text { by supporting idea } \\
\text { development, } \\
\text { organizing and } \\
\text { prioritizing } \\
\text { information and the } \\
\text { discovery of hidden } \\
\text { connections. }\end{array}$ & $\begin{array}{l}\text { GO provide structure, } \\
\text { guide thought and } \\
\text { focus attention for } \\
\text { thinking 'in-the-box'. } \\
\text { Support learning of a } \\
\text { new concept }\end{array}$ \\
\hline $\begin{array}{l}\text { Supported phase } \\
\text { in BMI }\end{array}$ & $\begin{array}{l}\text { Mainly initiation } \\
\text { (Possible support for } \\
\text { integration) }\end{array}$ & $\begin{array}{l}\text { Mainly ideation } \\
\text { (Possible support } \\
\text { for initiation) }\end{array}$ & $\begin{array}{l}\text { Mainly integration } \\
\text { (Possible support for } \\
\text { initiation) }\end{array}$ \\
\hline $\begin{array}{l}\text { Used graphic } \\
\text { elements }\end{array}$ & $\begin{array}{l}\text { Boxes and bubbles } \\
\text { (for objects, } \\
\text { concepts, ideas), } \\
\text { linked by connectors } \\
\text { or arrows with } \\
\text { potential description } \\
\text { (e.g. "consists of") }\end{array}$ & $\begin{array}{l}\text { Central topic } \\
\text { bubble, bubbles in } \\
\text { descending } \\
\text { hierarchical levels } \\
\text { with different colors } \\
\text { or bubbles, branches } \\
\text { between concepts, } \\
\text { optional symbols }\end{array}$ & $\begin{array}{l}\text { Labelled boxes or } \\
\text { other graphic forms } \\
\text { with description fields } \\
\text { to be filled out, either } \\
\text { with text, images, or } \\
\text { combinations of them }\end{array}$ \\
\hline $\begin{array}{l}\text { Complementary } \\
\text { content }\end{array}$ & $\begin{array}{l}\text { Mainly causal view } \\
\text { or transactional view }\end{array}$ & $\begin{array}{l}\text { Mainly the elements } \\
\text { view }\end{array}$ & $\begin{array}{l}\text { Mainly the elements } \\
\text { view }\end{array}$ \\
\hline Examples & $\begin{array}{l}\text { Representation } \\
\text { based on causal loop } \\
\text { diagrams } \\
\text { (Casadesus- } \\
\text { Masanell and Ricart, } \\
\text { 2007) }\end{array}$ & $\begin{array}{l}\text { Mind map } \\
\text { (Gavrilova et al., } \\
\text { 2014) }\end{array}$ & $\begin{array}{l}\text { Business Model } \\
\text { Canvas (Osterwalder } \\
\text { and Pigneur, 2010) }\end{array}$ \\
\hline
\end{tabular}

Brainstorming webs are characterized by open-endedness, hierarchical structuring, flexible granularity, and cross-linking of concepts; hence, they represent effective tools to support the ideation of creative ideas (Hyerle, 2009). Creativity is associated, among others, with the skills of fluid reasoning (Nusbaum and 
Silvia, 2011), divergent thinking (Batey et al., 2009), and working memory (de Dreu et al., 2012). Almost all the brainstorming webs in the sample are mind maps. Mind-mapping is a technique for improving creativity, but also for "grappling with massive and complex subjects" (Buzan and Buzan, 2006). The depiction of a business model as a mind map therefore supports not only the ideation phase, but can also support the initiation phase by absorbing complexity. Through unbounded branching, the business modeler can shift between different levels of reasoning, while freeing working memory. Brainstorming webs convey at most the business model elements, yet modelers can further integrate the causal view by relating the concepts elaborated in the mind map to each other. While the mind-mapping process has been clearly linked to cognitive support during creative tasks, it is not yet researched whether the outcome of using similar methods (the brainstorming web in general) are conducive to business model innovation when they are used as stand-alone artefacts. Summarizing, such methods seem to be supportive to the BMI process, whereas other graphic forms might be better suited for visual knowledge representation.

Conceptual maps reveal (hidden) relationships between concepts and ideas, while absorbing complexity. This type of cognitive support is required in the initiation phase (Table 1). Through the rigorous representation of causal dependencies, conceptual maps uncover the inconsistencies in the current business model and can graphically reveal the potential for a change in its core logic (Massa and Tucci, 2014). Furthermore, conceptual maps that represent the entire causal or transactional relationships can guide and structure thinking in the integration phase. In the sample, we identify several representations that rely on conceptual modelling and represent the business model in a way that is specific to the purpose of analysis (Gordijn and Akkermans, 2001; Grasl, 2009; Groesser and Jovy, 2016; Kley et al., 2011; Kundisch and John, 2011; Weiner et al., 2010) or in a way that aims to achieve integration in the design process (Abdelkafi and Täuscher, 2014; Casadesus-Masanell and Ricart, 2011; Schallmo and Brecht, 2010). In particular, when such representations are used for integrative purposes, researchers tend to combine a causal view with an elements view. The fact that these types of structured visualizations have not been identified in the practitioner sample can either be due to our methodology, since companies might be reluctant to publish them online, or to a lack of usage of formal notations among practitioners. While some of the formally 
developed conceptual mapping approaches have been empirically evaluated by their developers (Gordijn and Akkermans, 2001; Grasl, 2009; Kundisch and John, 2011), empirical knowledge on whether conceptual maps can support specific cognitive processes better than other visual representations has still to be produced.

Our research has focused on the existing visual representations of business models. In spite of their large variety and heterogeneity, there are further visual options to be considered. Lengler and Eppler (2007) have conducted extensive research that aims to identify and categorize the visualization methods applied in different management fields. They find around 100 visual methods that they classify by using a structure that is similar to the periodic table of chemical elements. Actually, we can see that only a small portion of these graphic forms has been applied to business models. To select a novel form for the visual representation of a BM, researchers and practitioners can get inspirations from such comprehensive repositories. For instance, the periodic table provides many visual methods such as concept skeleton, visual metaphors, twoby-two 'magic quadrants' or radar charts that could support convergent thinking.

It is important to emphasize that the application of the selected visual tools presume an alignment of these tools with the firm's current innovation and cognitive challenges. Visual tools for business models are obviously useful for firms that are conscious of the importance of changing their organizations to accommodate new business models. Not all types of firms are, however, equally incentivized to ideate highly innovative business models. The potential rewards for developing an innovative business model depends on a number of contextual factors such as the firm's strategy, its organizational characteristics and capabilities as well as its market environment (Teece, 2010). There are strategic and organizational challenges that may keep firms from business model innovation. With respect to cognitive challenges, business model research starts to provide a better understanding about the cognitive processes that are active in different phases of BMI. Recent research has shown that managerial teams can consciously generate ideas for new business models by making use of two cognitive processes: analogical reasoning and conceptual combination (Martins, Rindova, \& Greenbaum, 2015). Both processes have in common that innovators 
convert an external stimulus from a different context (e.g. a business model from another industry) into a creative idea for their context. While analogical reasoning focuses on recognizing relations between objects (i.e. the business model elements) and adapting these relations, conceptual combination focuses on differences in attributes between the stimulus and the own design problem to adapt individual attributes (Martins et al., 2015). This leads to a process for ideating new business models that center around the representation of the source business model (the stimulus) and the structured comparison of attributes (business model elements) as well as their relations with the firm's business model. This theoretical proposition has important implications for the choice of appropriate visual tools. To find out the differences in the relations between elements (for analogical reasoning), the usage of conceptual maps is most supportive (Hyerle, 2009). The differences at the elements level (for conceptual combination) are best identified by using graphic organizers as complementary tools (Hyerle, 2009). Morphological boxes can be used in this regard to differentiate between elements of the business model (Im and Cho, 2013; Kley et al., 2011).

Visual representations are rarely applied as a stand-alone tool. Although the visual representations reviewed in this work are taken in isolation, we acknowledge the importance of combining them with complementary tools. Scholars have proposed methods and artefacts to purposefully support the ideation of novel business models. These methods include, among others, the description of successful BMIs and the development of taxonomies or design patterns. Eurich et al. (2014) review the strengths and weaknesses of these approaches and propose a structured process that is combined with visual methods. For instance, the identification of business model patterns to stimulate analogical reasoning has gained increasing adoption in business model ideation methods (Abdelkafi et al., 2013; Amshoff et al., 2015; Gassmann et al., 2014; Mikusz et al., 2015). In addition, Osterwalder and Pigneur (2010) describe many tools from design thinking to design and innovate business models. Examples for such tools are empathy maps, customer journeys, brainstorming with post-it notes, prototyping, storytelling and scenario development. Recent research rooted in design thinking has suggested the use of games for the generation of novel business model ideas (Gudiksen, 2015). Gudikson (2015) also provides a comprehensive illustration of how three different forms of serious gaming 
can be applied as a form of experimentation in BMI. These different forms of design support, however, all center or at least build upon forms of visual representations. In conclusion, these studies point to the potential of combining visual representations with established design (thinking) methods in a systematic, principlecentered way toward the design of innovative business models.

\section{Contribution to business model research}

This work contributes to business model research in many ways. First, it provides a classification of competing business model understandings, which can be seen as a response to the criticism that $\mathrm{BM}$ literature does not move forward towards a common understanding of the BM concept (Arend, 2013). Some scholars propose that, instead of converging towards one definition, the academic discussion should clearly emphasize the differences between a limited number of streams (Zott and Amit, 2013). While the distinction between BMs as something real or as purely cognitive representations can provide important structure to the academic BM literature, it is not necessarily conducive to advancing the effective design of supporting artefacts for BMI in practice. This paper rather makes an important contribution towards the identification of different business model understandings from a practice-oriented perspective by analyzing the contents and graphic forms of business model visualizations, rather than focusing on competing theoretical perspectives. The distinction between the elements view, the transactional view, and the causal view can drive the focus of discussions from the detection of competing theoretical underpinnings towards differences in the actual use of the business model concept. Scholars can use the framework to clarify whether they define a business model as a set of key elements, a system of transactions between the business and its stakeholders, or a system of key choices and consequences and their causal interdependencies.

Second, this research contributes to design-oriented BM research by advancing the understanding of how visual artefacts are currently used outside academia. The novel sampling approach of VBMRs can generate important stimuli for designing effective BM artefacts. The initial sample of 1000 images revealed the Business Model Canvas by Osterwalder and Pigneur (2010) as the most popular visual representation of business models. Innovation literature has recently started to explore how standards can become an 
important enabler and driver of innovation (e.g. Abdelkafi et al., 2016; Abdelkafi and Makhotin, 2016). The use of the Business Model Canvas as a standardized representation for the description of the business model elements might increase the compatibility of research findings and their transferability to practitioners, thus driving business model innovation in practice. It should be noted, however, that as a graphic organizer, the Business Model Canvas may support holistic and structured BM design, but may not optimally foster the cognitive abilities required for BM ideation (Amit and Zott, 2015; Martins et al., 2015). As in the case of the business model canvas, which has originated from Osterwalder (2004)'s work on business model ontology, a quite complex academic concept that may not appeal to practitioners, other visual representations from the academic realm may benefit from intelligent simplification and standardization. For instance, previous work has shown the potential of causal representations for sparking new BM ideas through the identification of entire design patterns that are not intuitively visible (Abdelkafi and Täuscher, 2014; Casadesus-Masanell and Ricart, 2011; Eurich et al., 2014; Täuscher and Abdelkafi, 2015). Nevertheless, these representations are rarely used in practice. Thus, a more standardized and practitionerfriendly approach to using CLDs for the analysis of business models could better diffuse the tool in practical settings and contribute to the design of effective artefacts for BMI. Future practitioner-oriented research could focus on how to distill such causal representations to their essence, while experimentally identifying the optimal level of complexity to be conveyed for the transfer of knowledge.

Third, the research contributes to the cognitive perspective on business models. By drawing on visualization literature and cognitive psychology, we identify key cognitive abilities that enable managers to overcome the barriers during the process of business model innovation. Based on this, we propose the visual tools that effectively support cognition at each of the BMI-related tasks (Initiation, Ideation, and Integration). Though the cognitive perspective on business models focuses primarily on managerial cognition processes, our research shifts attention to artefacts that support the cognitive abilities of managers. Further research could study how managerial cognition influences the choice of visual artefacts, and whether, in turn, the artefact choices have a direct impact on managerial cognition and BMI-related decisions. 


\section{Conclusions}

Visual artefacts can support different tasks in the BMI process. However, not all visualizations are equally suited for the initiation, ideation, and integration phase of BMI. The developed repository of business model visualizations can support researchers and practitioners in selecting an appropriate visual representation to achieve specific tasks and mitigate cognitive challenges. To facilitate the selection, we have analyzed the graphic forms of 95 visual representations by applying a categorization from visualization research. Graphic organizers, which are found to constitute the majority of representations in the sample, are most suited to support the integration phase, but do not necessarily support adequately the cognitive processes required in ideation. Consequently, we encourage business model scholars to conduct further research on the relation between specific types of visual representations and their effectiveness in supporting cognitive functions for business model initiation, ideation, and integration. Moreover, the analysis of the textual and graphical components of all 95 business model visualizations allowed the development of a framework that classifies business model understandings into an elements view, a transactional view, and a causal view. The categorization of the visual representations has shown that these perspectives are complementary, and scholars as well as managers can actually combine them to generate more integrated views on business models. As a consequence, our research advances the academic discussion on business models by synthesizing the variety of interpretations into three distinctive, yet complementary views.

Our work opens directions for future research in other design-oriented research areas. Most importantly, it has the potential to contribute to the stream of design science research that develops software tools for BMI (e.g. Ebel et al., 2016; Giessmann and Legner, 2016; Peters et al., 2015). A recent review of the information systems (IS) literature suggests that software tools for BMI should be strongly grounded in the cognitive fit theory in order to align these artefacts with actual cognitive processes (Veit et al., 2014). Hence, our findings can support the design of effective software tools by encouraging scholars in the area of information systems to combine multiple forms of visualization and provide guidelines on their effective usage for different BMI tasks. 
The research is not without limitations. As acknowledged above, there is a potential bias in the search strategy based on the Google image search. Companies might have adopted more formal notations to represent business models internally, but might choose to not share these visualizations publicly. In addition, the chosen methodology has focused on visual representations in an isolated form. While this has allowed identifying novel patterns of representing business models, it does not provide reliable information on how they applied in managerial practice. Further research could use ethnographic methods to study the usage of visual methods directly in corporate settings to identify the usage of visual tools. Finally, our methodology for analyzing the VBMRs relied on information about the purpose of the representation as provided by the respective authors. Since many sources did not clearly state the purpose of the developed visual representation, the assignment is to a certain degree based on our interpretation of the authors' intentions. Consequently, our research can be considered a call for a more effective artefact design that defines the addressed BMI phase and cognitive barriers, while leveraging the existing knowledge from cognition research. 


\section{References}

Abdelkafi, N., Makhotin, S., 2016. Standardization, innovation, and organization: A contingency perspective, in: Effective standardization management in corporate settings. Business Science Reference, Hershey, PA, USA, pp. 286-308.

Abdelkafi, N., Makhotin, S., Posselt, T., 2013. Business model innovations for electric mobility - what can be learned from existing business model patterns? Int. J. Innov. Mgt. 17 (01), 1-41. 10.1142/S1363919613400033.

Abdelkafi, N., Makhotin, S., Thuns, M., Pohle, A., Blind, K., 2016. To Standardize or to patent? Development of a Decision Making Tool and Recommendation for Young Companies, in: Proceedings of XXVII ISPIM Innovation Conference. Blending Tomorrow's Innovation Vintage, Porto, Portugal. Jun 19 - 22.

Abdelkafi, N., Täuscher, K., 2014. Understanding the Basic Functioning of Business Models. Proceedings of XXV ISPIM Conference, Dublin, Ireland.

Abdelkafi, N., Täuscher, K., 2016. Business Models for Sustainability From a System Dynamics Perspective. Organization \& Environment 29 (1), 74-96. 10.1177/1086026615592930.

Amit, R., Zott, C., 2001. Value Creation in e-Business. Strategic Management Journal 22 (6-7), 493-520. 10.1002/smj.187.

Amit, R., Zott, C., 2015. Crafting Business Architecture: The Antecedents of Business Model Design. Strategic Entrepreneurship Journal 9 (4), 331-350. 10.1002/sej.1200.

Amshoff, B., Dülme, C., Echterfeld, J., Gausemeier, J., 2015. Business model patterns for disruptive technologies. International Journal of Innovation Management 19 (3). 10.1142/S1363919615400022.

Arend, R.J., 2013. The business model: Present and future--beyond a skeumorph. Strategic Organization 11 (4), 390-402. 10.1177/1476127013499636.

Aspara, J., Hietanen, J., Tikkanen, H., 2010. Business model innovation vs replication: Financial performance implications of strategic emphases. Journal of strategic marketing 18 (1), 39-56.

Aversa, P., Haefliger, S., Rossi, A., Baden-Fuller, C., 2015. Business Models and Modelling: Modularity and Manipulation, in: Baden-Fuller, C., Mangematin, V. (Eds.), Business Models and Modelling. Emerald Group Publishing Limited, pp. 151-185.

Baden-Fuller, C., Haefliger, S., 2013. Business Models and Technological Innovation. Long Range Planning 46 (6), 419-426. 10.1016/j.lrp.2013.08.023.

Baden-Fuller, C., Mangematin, V., 2013. Business models: A challenging agenda. Strategic Organization 11 (4), 418-427. 10.1177/1476127013510112.

Baden-Fuller, C., Morgan, M.S., 2010. Business models as models. Long Range Planning 43 (2-3), 156171. 10.1016/j.lrp.2010.02.005.

Batey, M., Chamorro-Premuzic, T., Furnham, A., 2009. Intelligence and personality as predictors of divergent thinking: The role of general, fluid and crystallised intelligence. Thinking Skills and Creativity 4 (1), 60-69. 10.1016/j.tsc.2009.01.002.

Berends, H., Smits, A., Reymen, I., Podoynitsyna, K., 2016. Learning while (re)configuring: Business model innovation processes in established firms. Strategic Organization 14 (3), 181-219. $10.1177 / 1476127016632758$.

Bettis, R.A., Prahalad, C.K., 2009. The dominant logic: Retrospective and extension. Strategy and globalization, $1-12$.

Bock, A.J., Opsahl, T., George, G., Gann, D.M., 2012. The Effects of Culture and Structure on Strategic Flexibility during Business Model Innovation. Journal of Management Studies 49 (2), 279-305. 10.1111/j.1467-6486.2011.01030.x. 
Bresciani, S., Tan, M., Eppler, M.J., 2011. Augmenting communication with visualization: Effects on emotional and cognitive response, in: Proceedings of the IADIS Int. Conf. ICT, Society and Human Beings 2011, Proceedings of the IADIS International Conference e-Democracy, Equity and Social Justice 2011, Part of the IADIS, MCCSIS 2011, pp. 11-18.

Bucherer, E., Eisert, U., Gassmann, O., 2012. Towards Systematic Business Model Innovation: Lessons from Product Innovation Management. Creativity and Innovation Management 21 (2), 183-198. 10.1111/j.1467-8691.2012.00637.x.

Buzan, T., Buzan, B., 2006. The Mind Map book. BBC Active, Essex, 328 pp.

Carayannis, E.G., Grigoroudis, E., Sindakis, S., Walter, C., 2014. Business Model Innovation as Antecedent of Sustainable Enterprise Excellence and Resilience. J Knowl Econ 5 (3), 440-463. 10.1007/s13132-014-0206-7.

Carayannis, E.G., Sindakis, S., Walter, C., 2015. Business Model Innovation as Lever of Organizational Sustainability. J Technol Transf 40 (1), 85-104. 10.1007/s10961-013-9330-y.

Card, S.K., Mackinlay, J.D., Shneiderman, B., 1999. Readings in information visualization: Using vision to think. Morgan Kaufmann Publishers, San Francisco, Calif., xvii, 686.

Casadesus-Masanell, R., Ricart, J.E., 2007. Competing through business models. Working Paper 713. IESE Business School.

Casadesus-Masanell, R., Ricart, J.E., 2010. From Strategy to Business Models and onto Tactics. Long Range Planning 43 (2-3), 195-215.

Casadesus-Masanell, R., Ricart, J.E., 2011. How to design a winning business model. Harvard Business Review 89 (1/2), 100-107.

Casadesus-Masanell, R., Zhu, F., 2013. Business model innovation and competitive imitation: The case of sponsor-based business models. Strategic Management Journal 34 (4), 464-482.

Chatterjee, S., 2013. Simple rules for designing business models. California management review : CMR $55(2), 97-124$.

Chesbrough, H., 2007. Business model innovation: It's not just about technology anymore. Strategy \& Leadership 35 (6), 12-17. 10.1108/10878570710833714.

Chesbrough, H., 2010. Business Model Innovation: Opportunities and Barriers. Long Range Planning 43, 354-363.

Chesbrough, H., Rosenbloom, R., 2002. The role of business model in capturing value from innovation: evidence from Xerox Corporation's technology spin-off companies. Industrial and Corporate Change $11(3), 529-555$.

DaSilva, C.M., Trkman, P., 2013. Business Model: What It Is and What It Is Not. Long Range Planning. 10.1016/j.lrp.2013.08.004.

de Dreu, C.K., Nijstad, B.A., Baas, M., Wolsink, I., Roskes, M., 2012. Working memory benefits creative insight, musical improvisation, and original ideation through maintained task-focused attention. Personality and Social Psychology Bulletin 38 (5), 656-669. 10.1177/0146167211435795.

Demil, B., Lecocq, X., 2010. Business Model Evolution: In Search of Dynamic Consistency. Long Range Planning 43 (2-3), 227-246. 10.1016/j.lrp.2010.02.004.

Doganova, L., Eyquem-Renault, M., 2009. What do business models do? Research Policy 38 (10), 15591570. 10.1016/j.respol.2009.08.002.

Dorst, K., 2011. The core of 'design thinking' and its application. Design Studies 32 (6), 521-532. 10.1016/j.destud.2011.07.006.

Doz, Y.L., Kosonen, M., 2010. Embedding Strategic Agility: A Leadership Agenda for Accelerating Business Model Renewal. Business Models 43 (2-3), 370-382. 10.1016/j.lrp.2009.07.006. 
Eppler, M.J., Bresciani, S., 2013. Visualization in management: From communication to collaboration. A response to Zhang. Journal of Visual Languages and Computing 24 (2), 146-149. 10.1016/j.jvlc.2012.11.003.

Eppler, M.J., Hoffmann, F., 2011. Challenges and visual solutions for strategic business model innovation, in: Strategies and Communications for Innovations: An Integrative Management View for Companies and Networks, pp. 25-36.

Eppler, M.J., Hoffmann, F., 2012. Does method matter? An experiment on collaborative business model idea generation in teams. Innovation: Management, Policy \& Practice 14 (3), 388-403. 10.5172/impp.2012.14.3.388.

Eppler, M.J., Hoffmann, F., Bresciani, S., 2011. New business models through collaborative idea generation. Int. J. Innov. Mgt. 15 (06), 1323-1341. 10.1142/S1363919611003751.

Eppler, M.J., Platts, K.W., 2009. Visual Strategizing. The Systematic Use of Visualization in the Strategic-Planning Process. Long Range Planning 42 (1), $42-74$.

Eurich, M., Weiblen, T., Breitenmoser, P., 2014. A six-step approach to business model innovation. International Journal of Entrepreneurship and Innovation Management 18 (4), 330-348. 10.1504/IJEIM.2014.064213.

Faber, E., Ballon, P., Bouwman, H., Haaker, T., Rietkerk, O., Steen, M., 2003. Designing business models for mobile ICT services, in: 16th Bled Electronic Commerce Conference eTransformation. 16th Bled Electronic Commerce Conference eTransformation, Bled, Slovenia,. June 9 - 11.

Frankenberger, K., Weiblen, T., Csik, M., Gassmann, O., 2013. The 4I-framework of business model innovation: A structured view on process phases and challenges. IJPD 18 (3/4), 249. 10.1504/IJPD.2013.055012.

Gassmann, O., Frankenberger, K., Csik, M., 2014. The business model navigator: 55 models that will revolutionise your business. Pearson, Harlow, $387 \mathrm{pp}$.

Gavrilova, T., Alsufyev, A., Yanson, A.-S., 2014. Transforming Canvas Model: Map versus Table. International Journal of Knowledge, Innovation and Entrepreneurship 2 (2), 51-65.

George, G., Bock, A.J., 2011. The Business Model in Practice and its Implications for Entrepreneurship Research. Entrepreneurship Theory and Practice 35 (1), 83-111.

Goethals, F., 2009. The Unified Business Model Framework. Working Paper, Lille, France, 47 pp.

Gordijn, J., Akkermans, H., 2001. Designing and evaluating e-business models. IEEE Intell. Syst. 16 (4), 11-17. 10.1109/5254.941353.

Gordijn, J., Osterwalder, A., Pigneur, Y., 2005. Comparing two business model ontologies for designing e-business models and value constellations. 18th Bled eConference eIntegration in Action Conference Proceedings.

Grasl, O., 2009. Professional Service Firms : Business Model Analysis - Method and Case Studies. Dissertation, St. Gallen, Switzerland.

Groesser, S.N., Jovy, N., 2016. Business model analysis using computational modeling: A strategy tool for exploration and decision-making. J Manag Control 27 (1), 61-88. 10.1007/s00187-015-0222-1.

Gudiksen, S., 2015. Business Model Design Games: Rules and Procedures to Challenge Assumptions and Elicit Surprises. Creativity and Innovation Management 24 (2), 307-322. 10.1111/caim.12114.

Hamel, G., 2000. Leading the revolution: How to thrive in turbulent times by making innovation a way of life. Plume, New York, NY, 337 pp.

Hedman, J., Kalling, T., 2003. The business model concept: Theoretical underpinnings and empirical illustrations. Eur J Inf Syst 12 (1), 49-59. 10.1057/palgrave.ejis.3000446. 
Hegarty, M., 2011. The cognitive science of visual-spatial displays: Implications for design. Topics in Cognitive Science 3 (3), 446-474. 10.1111/j.1756-8765.2011.01150.x.

Horsti, A., 2007. Essays on electronic business models and their evaluation. Working Paper, Helsinki, Finland.

Hoveskog, M., Halila, F., Danilovic, M., 2015. Early Phases of Business Model Innovation: An Ideation Experience Workshop in the Classroom. Decision Sciences Journal of Innovative Education 13 (2), 177-195. 10.1111/dsji.12061.

Hyerle, D., 2009. Visual tools for transforming information into knowledge. Corwin Press, Thousand Oaks, CA, xx, 167.

Im, K., Cho, H., 2013. A Systematic Approach for Developing a New Business Model Using Morphological Analysis and Integrated Fuzzy Approach. Expert Syst. Appl. 40 (11), 4463-4477. 10.1016/j.eswa.2013.01.042.

Kamoun, F., 2008. Rethinking the Business Model with RFID. Communications of the Association for Information Systems 22 (1).

Kiani, B., Gholamian, M.R., Hamzehei, A., Hosseini, S.H., 2009. Using Causal Loop Diagram to Achieve a Better Understanding of e-Business Models. International Journal of Electronic Business Management 7 (3), 159-167.

Kim, W.C., Mauborgne, R., 2014. Blue ocean leadership. Harvard Business Review 92 (5).

Kley, F., Lerch, C., Dallinger, D., 2011. New business models for electric cars-A holistic approach. Energy Policy 39 (6), 3392-3403. 10.1016/j.enpol.2011.03.036.

Kundisch, D., John, T., 2011. Business model representation incorporating real options: An extension of e3-value, in: Proceedings of the Annual Hawaii International Conference on System Sciences, pp. 4456-4465.

Kundisch, D., John, T., Honnacker, J., Meier, C., 2012. Approaches for business model representation: An overview. Multikonferenz Wirtschaftsinformatik 2012, 1821-1832.

Larkin, J.H., Simon, H.A., 1987. Why a Diagram is (Sometimes) Worth Ten Thousand Words. Cognitive Science 11 (1), 65-100. 10.1016/S0364-0213(87)80026-5.

Lerch, C., Selinka, G., 2010. Dynamics of Business Models - Long-ranging Impact Assessment of Business Models in the Capital Goods Industry. 28th International Conference of the System Dynamics Society, 2010, Seoul (Korea).

Lilien, G.L., 2011. Bridging the academic-practitioner divide in marketing decision models. Journal of Marketing 75 (4), 196-210.

Linder, J., Cantrell, S., 2000. Changing Business Models: Surveying The Landscape. Accenture Institute for Strategic Change, Cambridge, MA.

Little, J.D.C., 1970. Models and managers: The concept of a decision calculus. Management science : journal of the Institute for Operations Research and the Management Sciences 16 (8), B466-B485.

Mahadevan, B., 2000. Business Models for Internet-based eCommerce: An Anatomy. California Management Review 42 (4), 55-69.

Martins, L.L., Rindova, V.P., Greenbaum, B.E., 2015. Unlocking the Hidden Value of Concepts: A Cognitive Approach to Business Model Innovation. Strategic Entrepreneurship Journal 9 (1), 99-117. 10.1002/sej.1191.

Mason, K., Spring, M., 2011. The sites and practices of business models. Industrial Marketing Management 40 (6), 1032-1041. 10.1016/j.indmarman.2011.06.032.

Massa, L., Tucci, C., 2014. Business Model Innovation, in: Dodgson, M., Gann, D., Phillips, N. (Eds.), The Oxford handbook of innovation management. Oxford Univ. Press, New York. 
McCormick, B.H., DeFanti, T.A., Brown, M.D., Zaritsky, R., 1987. Visualization in scientific computing. ACM SIGGRAPH; [Order from] ACM Order Dept, [New York, N.Y.], Baltimore, Md., 1 volume (various.

McGrath, R., 2010. Business Models: A Discovery Driven Approach. Long Range Planning 43 (2-3), 247-261.

Mikusz, M., Jud, C., Schäfer, T., 2015. Business model patterns for the connected car and the example of data orchestrator, in: Lecture Notes in Business Information Processing, vol. 210, pp. 167-173.

Mitchell, D., Coles, C., 2003. The ultimate competitive advantage of continuing business model innovation. Journal of Business Strategy 24 (5), 15-21. 10.1108/02756660310504924.

Novak, J.D., Cañas, A.J., 2008. The Theory Underlying Concept Maps and How to Construct Them: Technical Report IHMC CmapTools. Florida Institute for Human and Machine Cognition. http://cmap.ihmc.us/Publications/ResearchPapers/TheoryUnderlyingConceptMaps.pdf.

Nusbaum, E.C., Silvia, P.J., 2011. Are intelligence and creativity really so different? Fluid intelligence, executive processes, and strategy use in divergent thinking. Intelligence 39 (1), 36-45. 10.1016/j.intell.2010.11.002.

O’Donnell, A., Dansereau, D., Hall, R., 2002. Knowledge Maps as Scaffolds for Cognitive Processing. Educational Psychology Review 14 (1), 71-86.

Osterwalder, A., 2004. The Business Model Ontology - A Proposition in a Design Science Approach. Dissertation, Lausanne, Switzerland.

Osterwalder, A., 2014. Value proposition design: How to create products and services customers want ; get started with. Wiley, Hoboken NJ u.a., XXV, 290 S.

Osterwalder, A., Pigneur, Y., 2010. Business model generation: A handbook for visionaries, game changers, and challengers, 1st ed. Wiley, Hoboken, NJ, 288 pp.

Pateli, A.G., Giaglis, G.M., 2004. A research framework for analysing eBusiness models. Eur J Inf Syst 13 (4), 302-314. 10.1057/palgrave.ejis.3000513.

Pedersen, E.R.G., Gwozdz, W., Hvass, K.K., 2016. Exploring the Relationship Between Business Model Innovation, Corporate Sustainability, and Organisational Values within the Fashion Industry. J Bus Ethics, 1-18. 10.1007/s10551-016-3044-7.

Phaal, R., Farrukh, C.J., Probert, D.R., 2009. Visualising strategy: A classification of graphical roadmap forms. International Journal of Technology Management 47 (4), 286-305. 10.1504/IJTM.2009.024431.

Plé, L., Lecocq, X., Angot, J., 2010. Customer-Integrated Business Models: A Theoretical Framework. M@n@gement 13 (4), 226-265.

Poel, M., Renda, A., Ballon, P., 2007. Business model analysis as a new tool for policy evaluation: Policies for digital content platforms. info 9 (5), 86-100. 10.1108/14636690710816471.

Pohle, G., Chapman, M., 2006. IBM's global CEO report 2006: Business model innovation matters. Strategy and Leadership 34 (5), 34-40. 10.1108/10878570610701531.

Prahalad, C.K., Bettis, R.A., 1986. The dominant logic: A new linkage between diversity and performance. Strategic Management Journal 7 (6), 485-501.

Samavi, R., Yu, E., Topaloglou, T., 2009. Strategic reasoning about business models: A conceptual modeling approach. Information Systems and e-Business Management 7 (2), 171-198. 10.1007/s10257-008-0079-z.

Schallmo, D.R.A., Brecht, L., 2010. Business Model Innovation in Business-to-Business Markets, Quebec City, Canada. https://www.uniulm.de/fileadmin/website_uni_ulm/mawi.inst.125/documents/research/pubications/Business_Model_I 
nnovation_in_Business-to-Business_Markets_-_Procedure_and_Examples_V08_DSC.pdf. Accessed 7 July 2016.

Schneider, S., Spieth, P., 2013. Business model innovation: Towards an integrated future research agenda. Int. J. Innov. Mgt. 17 (1), 1340001.

Schuster, R., Motal, T., 2009. From e3-value to REA: Modeling Multi-party E-business Collaborations, in: 2009 IEEE Conference on Commerce and Enterprise Computing (CEC), Vienna, Austria, pp. 202208.

Seelos, C., Mair, J., 2007. Profitable Business Models and Market Creation in the Context of Deep Poverty: A Strategic View. Academy of Management Perspectives 21 (4), 49-63. 10.5465/AMP.2007.27895339.

Shafer, S.M., Smith, H.J., Linder, J.C., 2005. The power of business models. Business Horizons 48 (3), 199-207. 10.1016/j.bushor.2004.10.014.

Shi, Y., Manning, T., 2009. Understanding business models and business model risks. The journal of private equity : JPE 12 (2), 49-59.

Sosna, M., Trevinyo-Rodríguez, R.N., Velamuri, S.R., 2010. Business Model Innovation through Trialand-Error Learning. Long Range Planning 43 (2-3), 383-407. 10.1016/j.1rp.2010.02.003.

Spieth, P., Schneckenberg, D., Ricart, J.E., 2014. Business model innovation - state of the art and future challenges for the field. R\&D Manage 44 (3), 237-247. 10.1111/radm.12071.

Suárez, F.F., Cusumano, M.A., Kahl, S.J., 2013. Services and the business models of product firms: An empirical analysis of the software industry. Management science : journal of the Institute for Operations Research and the Management Sciences 59 (2), 420-435.

Täuscher, K., Abdelkafi, N., 2015. Business Model Robustness: A System Dynamics Approach, in: Proceedings of 15th EURAM conference. Uncertainty is a great opportunity., Warsaw, Poland. 1720 June.

Teece, D.J., 2010. Business Models, Business Strategy and Innovation. Long Range Planning 43 (2-3), 172-194.

These phenomena and questions fundamentally motivate current business model research as evidenced by a recent calls for future business model research by (Demil et al. 2015):, 2015. Introduction to the SEJ Special Issue on Business Models: Business Models within the Domain of Strategic Entrepreneurship. Strategic Entrepreneurship Journal 9 (1), 1-11. 10.1002/sej.1194.

Timmers, P., 1998. Business Models for Electronic Markets. Electronic Markets 8 (2), 3-8.

Tversky, B., 2011. Visualizing thought. Topics in Cognitive Science 3 (3), 499-535. 10.1111/j.17568765.2010.01113.x.

Upton, A.W., 1961. Design for thinking. Stanford Univ. Pr, Stanford, Cal., x, 240 S. 8.".

Velu, C., Stiles, P., 2013. Managing decision-making and cannibalization for parallel business models. Long range planning : LRP ; international journal of strategic management 46 (6), 443-458.

Weill, P., Vitale, M.R., 2001. Place to space: Migrating to ebusiness models. Harvard Business School Press, Boston, Mass, xvi, 372.

Weiner, N., Renner, T., Kett, H., 2010. Geschäftsmodelle im Internet der Dienste: Aktueller Stand in Forschung und Praxis, Stuttgart. https://wiki.iao.fraunhofer.de/images/studien/geschaeftsmodelle_im_internet_der_dienste_trends.pdf. Accessed 7 July 2016.

Weiner, N., Weisbecker, A., 2011. A Business Model Framework for the Design and Evaluation of Business Models in the Internet of Services, San Jose, California, USA. 
Wirtz, B.W., 2011. Business model management: Design - instruments - success factors, 1st ed. Gabler, Wiesbaden, XII, $342 \mathrm{~S}$.

Zhang, K., 2012. Using visual languages in management. Journal of Visual Languages \& Computing 23 (6), 340-343. 10.1016/j.jvlc.2012.09.001.

Zott, C., Amit, R., 2007. Business Model Design and the Performance of Entrepreneurial Firms. Organization Science 18 (2), 181-199. 10.1287/orsc.1060.0232.

Zott, C., Amit, R., 2008. The fit between product market strategy and business model: implications for firm performance. Strategic Management Journal 29 (1), 1-26. 10.1002/smj.642.

Zott, C., Amit, R., 2010. Business Model Design: An Activity System Perspective. Long Range Planning 43 (2-3), 216-226. 10.1016/j.lrp.2009.07.004.

Zott, C., Amit, R., 2013. The business model: A theoretically anchored robust construct for strategic analysis. Strategic Organization 11 (4), 403-411.

Zott, C., Amit, R., Massa, L., 2011. The Business Model: Recent Developments and Future Research. JOM 37 (4), 1019-1042. 